\title{
Partial bleaching in an assemblage of small apozooxanthellate corals of the genera Heteropsammia and Heterocyathus
}
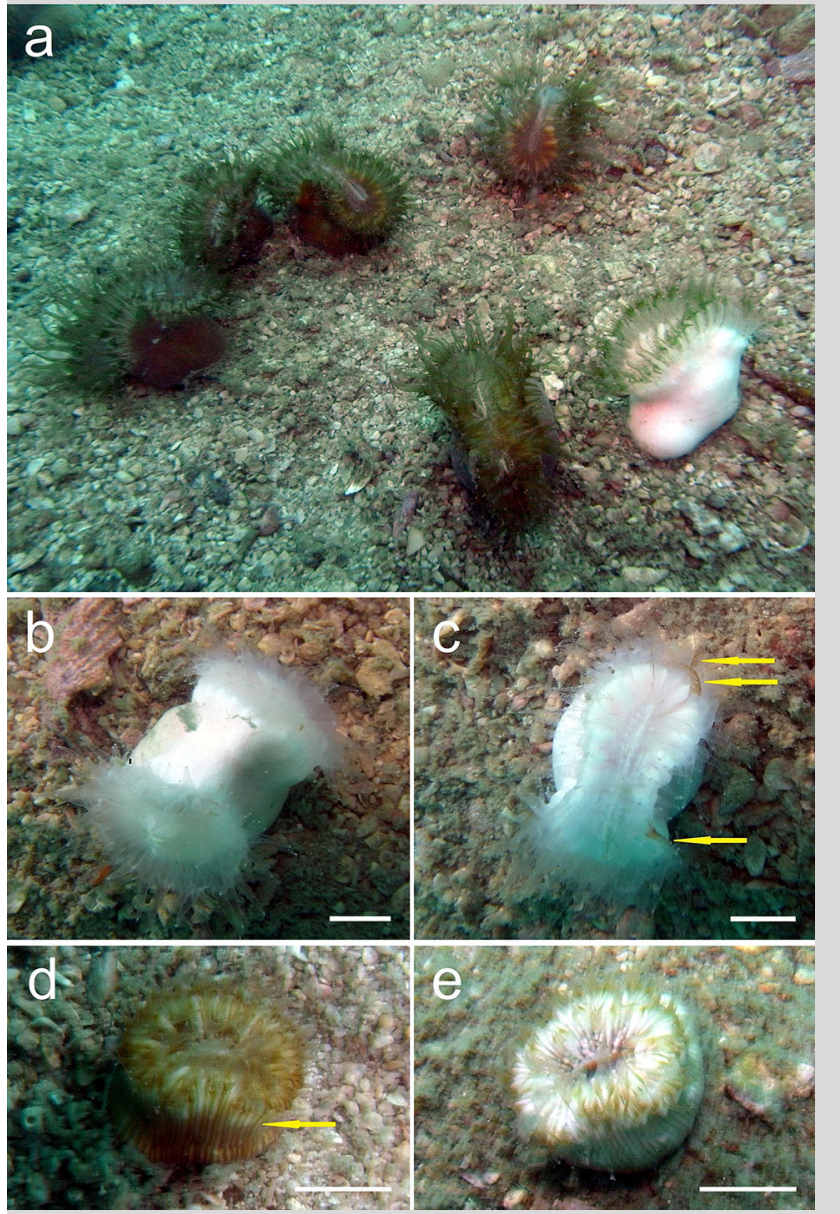

Fig. 1 Unbleached, bleached, and partially bleached Heteropsammia and Heterocyathus corals at Koh Tao (scale bars $0.5 \mathrm{~cm}$ ). a Six specimens of Heteropsammia cochlea, one of them bleached (tentacles excepted). b A completely bleached $H$. cochlea with two polyps. c $H$. cochlea with zooxanthellae in three tentacles (arrows). d Heterocyathus aequicostatus bleaching at upper part (above arrow). e Nearly completely bleached $H$. aequicostatus
Corals of the genera Heteropsammia (Dendrophylliidae) and Heterocyathus (Caryophylliidae) consist of a small $(<2.5 \mathrm{~cm})$, free-living, single polyp that is pulled over sandy substrates by an endosymbiotic sipunculan worm (Hoeksema and Best 1991). They are considered to have a facultative symbiotic relationship with Symbiodinium zooxanthellae, by their presence at shallow depths (such as $<40 \mathrm{~m}$ ) and their absence at much greater depths (Hoeksema and Best 1991). Species of these genera should therefore be considered apozooxanthellate (Schuhmacher and Zibrowius 1985). However, the deep records are mostly based on studies of dry museum material, which could no longer be checked for the presence of zooxanthellae.

On February 18, 2011, an assemblage of Heteropsammia cochlea (Spengler, 1781) and Heterocyathus aequicostatus (Milne Edwards and Haime, 1848) was studied on a sandy bottom (16-19 m depth) near a coral reef at Koh Tao, Gulf of Thailand $\left(10^{\circ} 7^{\prime} 12^{\prime \prime} \mathrm{N}, 99^{\circ} 48^{\prime} 60^{\prime \prime} \mathrm{E}\right)$. At that time, reef corals at this island were recovering from a major bleaching event that took place mid-2010. Although this event was over, some of the Heteropsammia and Heterocyathus corals showed partial or complete bleaching (Fig. 1). This is noteworthy because individuals of these small species have not been reported to bleach before in shallow water despite various accounts of interspecific variation in bleaching susceptibility among reef corals (e.g., Guest et al. 2012). The present observations confirm that these free-living corals usually contain zooxanthellae in shallow water and that it is possible that they may occur without symbiotic algae at greater depths.

\section{References}

Guest JR, Baird AH, Maynard JA, Muttaqin E, Edwards AJ, Campbell SJ, Yewdall K, Affendi YA, Chou LM (2012) Contrasting patterns of coral bleaching susceptibility in 2010 suggest an adaptive response to thermal stress. PLoS One 7(3):e33353

Hoeksema BW, Best MB (1991) New observations on scleractinian corals from Indonesia: 2. Sipunculan-associated species belonging to the genera Heterocyathus and Heteropsammia. Zool Meded 65:221-245

Schuhmacher H, Zibrowius H (1985) What is hermatypic? A redefinition of ecological groups in corals and other organisms. Coral Reefs 4:1-9

B. W. Hoeksema $(\bowtie)$

Department of Marine Zoology, Naturalis Biodiversity Center, P.O. Box 9517, 2300 RA Leiden, The Netherlands

e-mail: bert.hoeksema@naturalis.nl

J. L. Matthews

Big Blue Conservation, Big Blue Dive Resort, Koh Tao 84360, Thailand

J. L. Matthews

School of Biological Sciences, Victoria University of Wellington, Wellington 6140, New Zealand 